\title{
Microstructure and mechanical properties of borided AISI T1 high-speed steel by dehydrated paste- pack boriding
}

Irving Morgado-González ${ }^{1}$, Martín Ortiz-Domínguez², Oscar Gómez-Vargas³ ${ }^{3}$ José Nieto-Sosa ${ }^{3}$, Cristian Monroy-Palafox ${ }^{4}$, María Ortiz-Ocampo ${ }^{3}$ and José Solís-Romero ${ }^{3}$

${ }^{1}$ Universidad Autónoma del Estado de Hidalgo, Mineral de la Reforma, Hidalgo, Mexico, ${ }^{2}$ Universidad Autónoma del Estado de Hidalgo, Ciudad Sahagún, Hidalgo, Mexico, ${ }^{3}$ Instituto Tecnológico de Tlalnepantla, Estado de México, México, Mexico, ${ }^{4}$ Universidad Autónoma del Estado de Hidalgo, Estado de México, México, Mexico

Nowadays hard layers are playing an important role in the wear protection for cutting and forming tools and on automotive components. Functional layers (for example, nitride layers, boride layers, and carbide layers) and decorative coatings also need wear protection, even though mechanical wear plays here a role in a somewhat different manner. The estimated market volume worldwide for hard coatings in 2015 was about US $\$ 2.6$ billion. Surface hardening treatments used in the metal-mechanic industry generally fall into two categories, diffusion (carburizing, nitriding, boriding, and carbo-boro-nitriding) and overlay coating (PVD) [110]. The objective of this study was to analyze the microstructure of the Fe2B layers formed on an AISI T1 high-speed steel and to study the wear properties of Fe2B layers. For tribological characterization, the DaimlerBenz Rockwell-C indentation technique was used to qualitatively assess the cohesion of boride layers on AISI T1 high-speed steel. Furthermore, the pin-on-disc test was employed in order to study the effect of the boriding treatment on wear behaviour of this steel. The specimen sizes are following MPIF STANDARD 41, the tested samples had a disc shape with a diameter of $25.4 \mathrm{~mm}$ and a thickness of $10 \mathrm{~mm}$. The chemical composition of the material is: $0.62-0.80 \% \mathrm{C}, 3.75-4.50 \% \mathrm{Cr}, 0.10-0.40 \% \mathrm{Mn}, 0.20-0.40 \% \mathrm{Si}, 0.90-1.30 \% \mathrm{~V}, 17.25-18.75 \%$ $\mathrm{W}, 0.03 \% \mathrm{P}$ and $0.03 \% \mathrm{~S}$ (weight \%). Dehydrated paste-pack boriding procedure was preferred in this study for its cost-effectiveness, and simplicity of the required equipment. The samples were embedded in a closed in a closed cylindrical case (see Fig. 1) having a dehydrated paste of boron powder mixture inside with an average particle size of $10 \mu \mathrm{m}$. Boriding mixture contains of B4C (active source of boron), Na3AlF6 (activator), $\mathrm{SiC}$ (inert filler), and $\mathrm{SiC} 8 \mathrm{H} 20 \mathrm{O} 4$ which is used to protect surfaces (see Fig. 2). The powder-pack boriding process was carried out in a conventional furnace under a pure argon atmosphere at 1123 for $2 \mathrm{~h}$ and $1273 \mathrm{~K}$ for $6 \mathrm{~h}$ of exposure respectively. Once the boriding treatment was finished the container was removed from the furnace and slowly cooled to room temperature. The hard samples were grinded with SiC abrasive paper up to grit 2500. Afterwards, the samples were polished using a diamond suspension with particle size of $6 \mu \mathrm{m}$, finishing with particle size of $3 \mu \mathrm{m}$. Figure 3 shows the cross-sections and the EDS analysis obtained by SEM (JEOL JSM-6360 LV at $20 \mathrm{kV}$ ) of boride layers on AISI T1 high-speed steel treated at $1273 \mathrm{~K}$ for 6 h. The morphology of produced hard layers was saw-toothed for all boriding conditions. Such observed peculiar morphology favoured the adhesion of boride layers on borided steels [11]. In addition, the occurrence of more or less pronounced saw-tooth morphology depends mainly on the concentration of alloying elements present in the matrix as observed in different ferrous alloys [12]. The cohesion of boride layers on AISI T1 steel was investigated by using the Daimler-Benz Rockwell-C indentation technique. Two borided samples treated (at $1123 \mathrm{~K}$ for $2 \mathrm{~h}$ and $1273 \mathrm{~K}$ for $6 \mathrm{~h}$ ) were then subjected to the cohesion tests. The damage around the indentation can be viewed by SEM and compared with a defined pattern of adhesion strength according to the VDI 3198 norm [13]. The damage to the boride layer was compared with the adhesion strength quality maps HF1-HF6. In general, the adhesion strength HF1 to HF4 are defined as sufficient adhesion, whereas HF5 and HF6 represent insufficient adhesion (HF is the German short form of adhesion strength) [13-14]. Figure 4 shows the SEM micrographs of the craters of indentation caused by applying a conical diamond indenter on the surfaces of tested samples. Radial cracks are generated at the perimeter of indentation as shown in Figure 4(a). The adhesion quality was found to be acceptable for the sample borided at $1123 \mathrm{~K}$ for $2 \mathrm{~h}$ according to H4 category. Figure 4(b) puts into evidence the presence of a small quantity of spots with flaking due to 
extended delamination at the vicinity of the indentation. The adhesion quality was also acceptable for the borided sample at $1273 \mathrm{~K}$ for $6 \mathrm{~h}$, following HF3 category. Compressive stresses are immediately induced under the indent after the cohesion test with generation of tensile stresses at the indentation perimeter [10]. The tribological tests caused wear scars on the flat specimens (discs). There were measurable grooves on the discs. The wear depth of each groove was measured using a Mitutoyo Surftest Profilometer with the JIS2001 norm. Due to the depth measurements (transverse to the length of the groove) were taken. The experimental average depth was taken from these measurements. The volume of a "perfect groove" could be calculated from this information as done in earlier studies. The profiles shown in Figure 5(a) and 5(b) show grooved features, demonstrating the two-body wear mechanism. Figure 5(a) indicates that the unborided surface of AISI T1 steel was more severely worn compared to the borided surface as shown in Figure 5(b). The wear behaviour of boride layers was investigated by performing the pin-on-disc test on both borided sample (at $1273 \mathrm{~K}$ for $6 \mathrm{~h}$ ) and untreated sample using a CSM tribometer. Figure 6, describes the evolution of friction coefficient as a function of sliding distance by comparing the frictional behaviour between borided and untreated samples. This pin-on-disc test was carried out by using a diamond indenter during sliding under dry conditions. It is noted that the borided sample has a friction coefficient lower than that of the unborided sample. The average friction coefficient for the untreated sample ranged from 0.306 to 0.295 while for the borided sample, it possesses a value of friction coefficient located between 0.246 and 0.253 . The obtained results regarding the values of friction coefficient are consistent with the data reported in the literature [10].

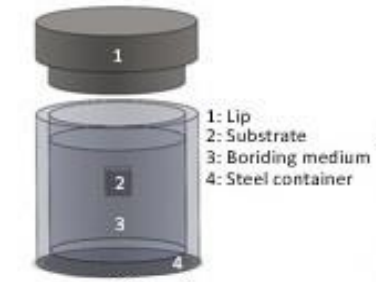

Fig. 1

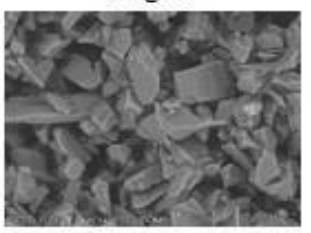

Fig. 2

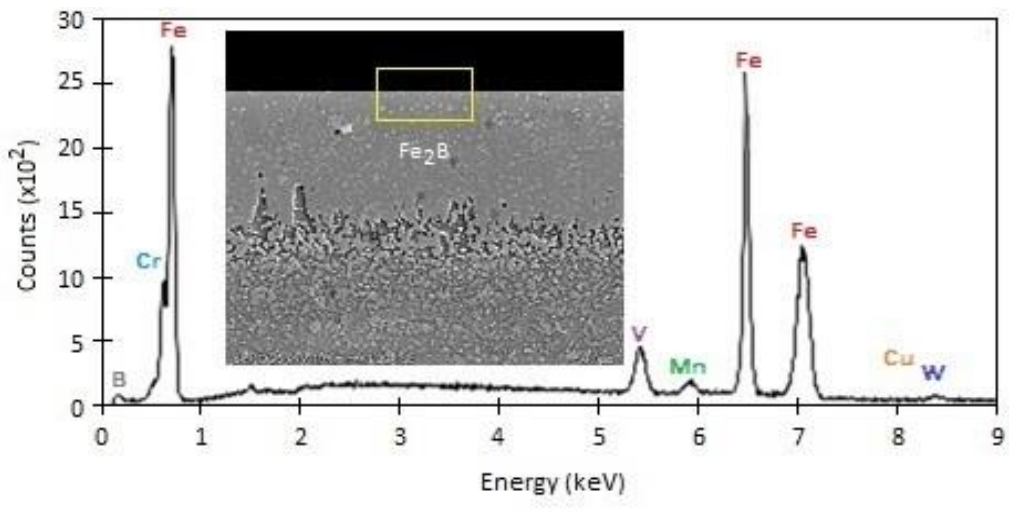

Fig. 3

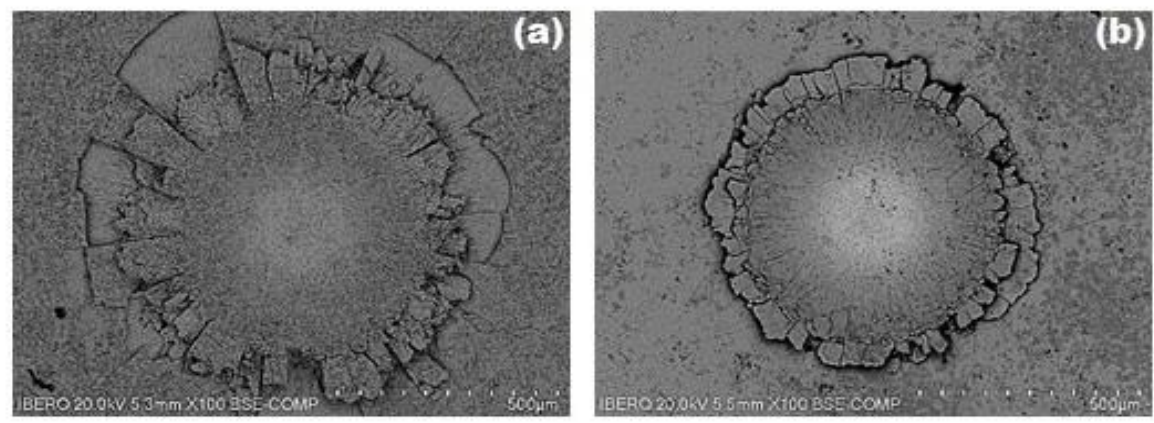

Fig. 4

Figure 1. Figure 1. Schematic view of the stainless steel AISI 316L container for the powder-pack treatments, Powder nitriding medium (Figure 1), Powder boriding medium (Figure 2), SEM cross-sectional micrograph and EDS spectrum at surface of the Fe2B layer developed on the surface of AISI T1 steel with $1273 \mathrm{~K}$ for $6 \mathrm{~h}$ (Figure 3) and SEM micrograph center of the indentation of VDI adhesion test on the borided AISI T1 steel samples: Figure 4(a) At a temperature of $1123 \mathrm{~K}$ with $2 \mathrm{~h}$ of exposure and Figure 4(b) with $6 \mathrm{~h}$ of exposure. 


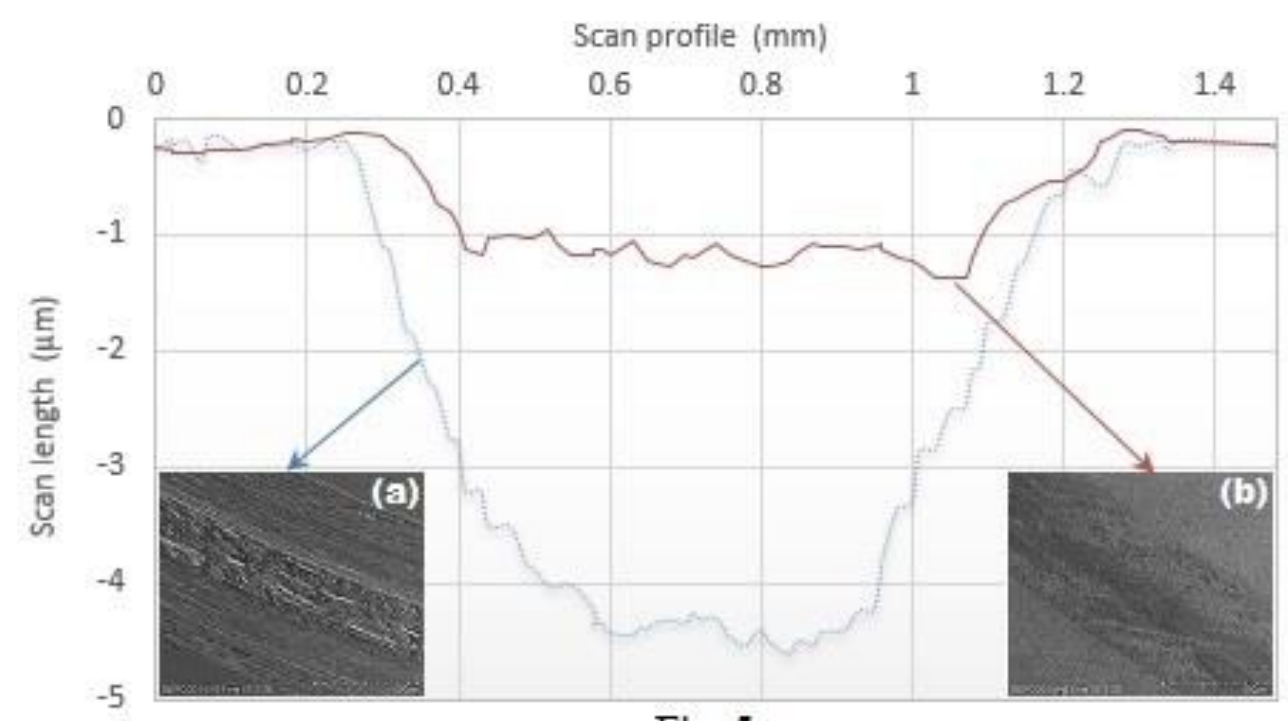

Fig. 5

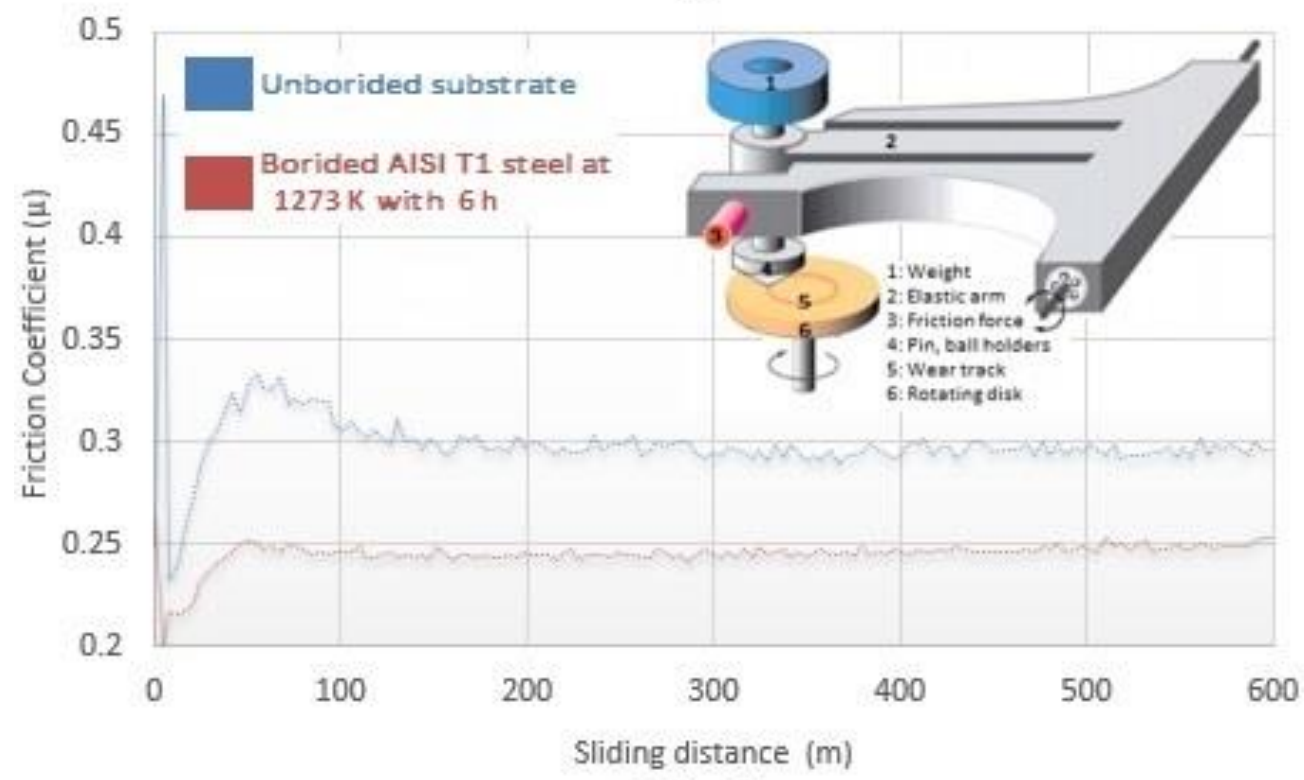

Fig. 6

Figure 2. Figure 5. Wear scar depth of the diamond-made indenter with a $10 \mathrm{~mm}$ diameter hemispheric, commonly employed, and was used to slide against on: 5(a) unborided AISI T1 steel and 5(b) borided at temperature $1273 \mathrm{~K}$ for $6 \mathrm{~h}$. Likewise, the variation of friction coefficient of diamond indenter during sliding against borided surface at $1273 \mathrm{~K}$ with exposure time of $6 \mathrm{~h}$ and unborided substrate (Figure 6).

\section{References}

[1] J. R. Davis. "Surface Hardening of Steels: Understanding the Basics", 1st ed. ASM, Ohio, p. 213.

[2] M. Ortiz-Domínguez, I. Morgado-González, A. Cruz-Avilés, A. Soto-García, R. Trujillo-Sánchez, M. L. Moreno-González, G. Moreno-González, O. A. Gómez-Vagas, J. Zuno-Silva, Microsc.Microanal. 25 (Suppl 2) 2019 , p. 2400.

[3] M. Ortiz-Domínguez, O. A. Gómez-Vargas, I. Simón-Marmolejo, M. A. Flores-Rentería, L. E. MartínezMartínez, A. Cruz-Avilés, M. A. Paredes-Rueda, Microsc. Microanal. 24 (Suppl 1) 2018, p. 1076.] 
[4] O. A. Gómez-Vagas, M. Ortiz-Domínguez, A. Cruz-Avilés, I. Morgado-González, J. Solis-Romero, V. A. Castellanos-Escamilla, E. Coronel-Guerra, E. Cardoso-Legorreta, Microsc. Microanal. 25 (Suppl 2) 2019, p. 770.

[5] O. A. Gómez-Vargas, M. Ortiz-Domínguez, J. Solís-Romero, A. Arenas-Flores, I. Morgado González, J. Zuno-Silva, F. R. Barrientos-Hernández and J. Medina-Marín, Microsc. Microanal. 25 (Suppl 2) 2019, p. 796. [6] M. Ortiz-Domínguez, O. A. Gómez-Vargas, G. Ares de Parga, G. Torres-Santiago, R. VelázquezMancilla, V. A. Castellanos-Escamilla, J. Mendoza-Camargo, and R. Trujillo-Sánchez, Advances in Materials Science and Engineering. 2019 (2019), p. 1.

[7] Graf von Matuschka A. "Boronizing“, 1st ed. Carl Hanser Verlag, Munich, p. 12.

[8] K. H. Habig, Mater. Eng. 2 (1980), p. 83.

[9] Martín Ortiz-Domínguez, Ángel Morales-Robles, Oscar Gómez-Vargas José Solís-Romero, Microsc. Microanal. 26 (Suppl 2) 2020, p. 2220.

[10] Martin Ortiz-Domínguez, Mourad Keddam, Milton Elias-Espinosa, Marius Ramírez-Cardona, Alberto Arenas-Flores, Jorge Zuno-Silva, Felipe Cervantes-Sodi and Edgar Cardoso-Legorreta, Metall. Res. Technol. 116 (2019), p. 11.

[11] T.S. Eyre, Wear. 34 (1975), p. 383.

[12] M. Carbucicchio, G. Palombarini, J. Mater. Sci. Lett. 10 (1987), p. 1147.

[13] N. Vidakis, A. Antoniadis, N. Bilalis, J. Mater. Process. Technol. 481 (2003), p. 143.

[14] S. Taktak, Mater. Des. 28 (2007), p. 1836. 